\title{
Development of Fluid Catalytic Cracking Distributed Simulator Based on IEC 61499
}

\section{Pengembangan Simulator Terdistribusi Proses Fluid Catalytic Cracking berbasis IEC 61499}

\author{
Wildan Fatkhurrohman ${ }^{\mathrm{a}, 1}$, Awang Noor Indra Wardana ${ }^{\mathrm{a}, 2, *}$, Ester Wijayanti ${ }^{\mathrm{a}, 3}$ \\ ${ }^{a}$ Department of Nuclear Engineering and Engineering Physics, Universitas Gadjah Mada, Jl. Grafika 2, Yogyakarta,55281, Indonesia \\ ${ }^{1}$ wildan.fatkhurrohman@mail.ugm.ac.id; ${ }^{2}$ awang.wardana@ugm.ac.id*; ${ }^{3}$ ester@ugm.ac.id \\ * corresponding author
}

\section{ARTICLE INFO}

Article history

Received January 23, 2020

Revised June 10, 2020

Accepted June 18, 2020

Keywords

Process Simulator

Fluid Catalytic Cracking

IEC 61499

Human Machine Interface

\section{ABSTRACT}

Fluid Catalytic Cracking (FCC) is one of the most important process units in oil refining. Operator skill is one of the determining factors for operational success. The operator cannot train his skills at the plant because it will endanger the ongoing process. Operators' skills can be trained through simulation media. This study developed an FCC model $I V$ process simulator to meet these needs. The application of the IEC 61499 standard uses to create simulation models based on IEC 61499 runtime environments (FORTE). Model validation based on reference simulations. The average percentage of error steady under normal operating conditions is $1.63 \%$. Mean Absolute Percentage Error (MAPE) values for changes in the coking factor, atmospheric temperature and feed temperature are $4.40 \%, 7.26 \%$, and $6.05 \%$, respectively. Modeling of FCC products on 6 components (gas oil, diesel oil, gasoline, light gas, liquid petroleum gas, and coke) was added as a simulation result. Percent of gas oil conversion between simulation results and plant data has an error of $0.12 \%$. The total fraction value of the components of the simulation results is 1.00 for each operating condition. The simulator interface in the form of a human-machine interface (HMI) was developed using Node-RED. Data communication between FCC simulation models on FORTE and HMI on Node-RED uses the Message Queuing Telemetry Transport (MQTT) communication protocol. Implementation of the IEC 61499 standard allows the simulation model to be distributed across several resources. The distribution of resources is done by simulating the FCC process to be run on several FORTE. The FCC simulation model distributed at 2, 4 , and 7 resources can reduce memory usage compared to the 1 centralized resource model by $18.0 \%, 36.0 \%$, and $48.8 \%$.

This is an open access article under the CC-BY-SA license.

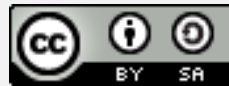

\section{Pendahuluan}

Fluid Catalytic Cracking (FCC) adalah salah satu unit proses penting pada kilang minyak [1,2]. FCC berperan sebagai perengkah residu minyak mentah rantai karbon panjang menjadi produk yang lebih bernilai jual seperti gasoline, liquid petroleum gas (LPG), dan light gas. Kesuksesan operasional FCC menjadi kunci untuk menentukan apakah kilang minyak tersebut dapat mempertahankan produk [2]. FCC harus dapat dioperasikan dalam keadaan stabil untuk jangka waktu yang lama serta meliputi periode start-up maupun shutdown. Operator harus memiliki keterampilan untuk dapat melakukan hal tersebut. Namun demikian, operator saat menjalankan FCC tidak memiliki banyak kesempatan melatih keterampilannya karena dapat membahayakan proses 
yang sedang berlangsung. Oleh karena itu, diperlukan sebuah simulator untuk melatih kemampuan operator.

Simulator dapat digunakan sebagai media yang efektif untuk melatih kemampuan operator. Operator dapat melatih kemampuannya dengan tanpa risiko terganggunya operasional FCC karena tidak dilakukan langsung pada FCC [3]. Makalah ini menerangkan tentang pengembangan sebuah simulator FCC sebagai upaya untuk memenuhi kebutuhan tersebut. Simulator FCC yang dikembangkan dapat dikelompokan menjadi tiga bagian utama yaitu model proses, antarmuka simulator, dan komunikasi data yang menghubungkan keduanya seperti terlihat pada Gambar 1 secara terdistribusi dengan menggunakan perangkat yang berbeda

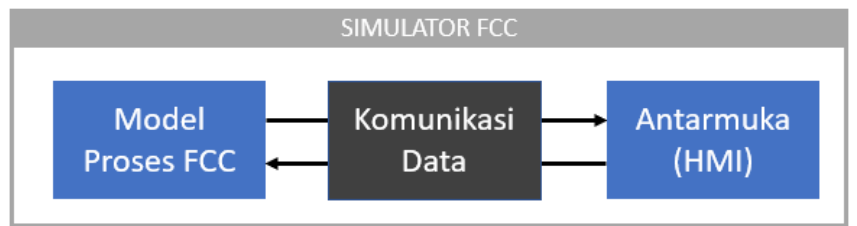

Gambar 1. Bagian utama pada Simulator FCC yang dikembangkan

\section{Metode}

\subsection{Implementasi Model Matematik Fluid Catalytic Cracking (FCC)}

Model matematik FCC merupakan bagian simulator yang berisi perhitungan persamaan proses. Model proses harus mampu mengambarkan dinamika FCC yang mendekati dengan kondisi FCC dilapangan. Model FCC dibuat dengan implementasi standar IEC 61499 pada 4DIAC-IDE.

Model matematik FCC [1] digunakan sebagai acuan pada pengembangan simulator ini. Model tersebut cukup lengkap menyajikan dinamika FCC yang terjadi. FCC menurut saat menjalankan FCC dimodelkan pada 7 bagian proses yaitu sistem umpan, pemanas awal, reaktor, kompresor, regenerator, blower udara, dan sirkulasi katalisator seperti yang terlihat pada Gambar 2.

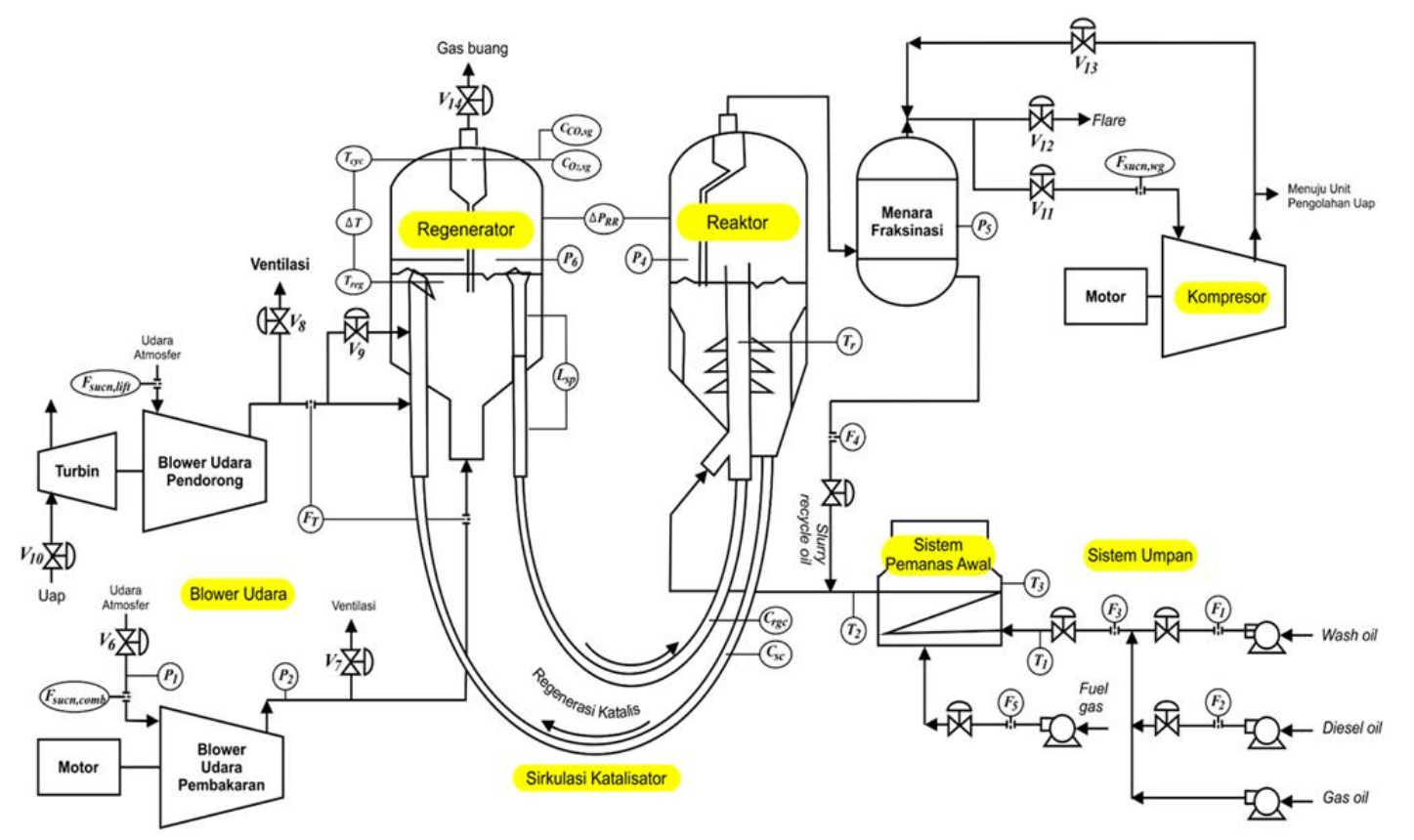

Gambar 2. Bagian proses pada FCC model IV [1]

Sistem umpan merupakan sistem yang berfungsi mengatur aliran umpan. Gas oil merupakan bahan utama yang direngkahkan pada FCC. Wash oil dan diesel oil ditambahkan kedalam model sistem sebagai umpan tambahan. Wash oil memiliki massa jenis yang lebih berat dibandingkan Gas oil, sedangkan Diesel oil lebih ringan [1]. Slurry recycle oil merupakan sisa Gas oil yang belum terengkahkan dan dialirkan kembali menuju reaktor. Pemanas awal berfungsi menaikkan suhu umpan sebelum memasuki reaktor. Reaksi perengkahan yang terjadi di dalam reaktor merupakan 
reaksi endotermik sehingga membutuhkan kalor untuk bereaksi. Kalor pada pemanas awal dihasilkan dari pembakaran fuel gas pada furnace. Perpindahan kalor terjadi melalui pipa penukar panas pada pemanas awal. Reaktor dan regenerator merupakan bagian utama pada unit FCC. Reaksi perengkahan terjadi pada riser di dalam reaktor. Umpan masuk ke dalam riser dicampurkan dengan katalis yang telah diregenerasi pada regenerator. Katalis digunakan untuk mempercepat reaksi perengkahan [3]. Reaksi akan menyebabkan penumpukan coke pada permukaan katalis sehingga mengurangi keaktifannya. Katalis tersebut kemudian dialirkan pada regenerator untuk diregenerasi. Regenerasi katalis di dalam reaktor dilakukan dengan cara membakar coke pada permukaan katalis. Reaksi pembakaran membutuhkan oksigen dari udara yang dialirkan oleh blower. Sirkulasi katalis antara reaktor dengan regenerator melalui pipa sirkulasi katalisator. Produk hasil perengkahan mengalir dari reaktor menuju menara fraksinasi karena adanya perbedaan tekanan. Perbedaan tekanan ini diatur oleh kompresor.

Keseluruhan model matematik acuan [1] yang digunakan dalam pengembangan simulator FCC terdiri dari seperangkat persamaan aljabar dan diferensial nonlinear yang dapat dinyatakan empat persamaan sebagai berikut:

$$
\begin{aligned}
& \frac{d x}{d t}=f(x, z, d, u) \\
& 0=g(x, z, d, u) \\
& y=m(x, z) \\
& a \leq(x, z, d, u) \leq b
\end{aligned}
$$

Persamaan (1) adalah persamaan keadaan yang merupakan persaman diferensial nonlinier model FCC dengan $\boldsymbol{x}$ sebagai vektor variabel keadaan, $\boldsymbol{z}$ sebagai vektor variabel aljabar, $\boldsymbol{d}$ sebagai vektor gangguan dan $\boldsymbol{u}$ sebagai vektor input. Persamaan (2) mewakili persamaan aljabar dalam model FCC serta seperangkat persamaan diferensial ordiner yang diintegrasikan. Persamaan (3) memodelkan vektor keluaran sistem yang merupakan variabel terukur $\boldsymbol{y}$ sedangkan Batasan-batasan sistem pada (4) dibatasi oleh $\boldsymbol{a}$ yang merupakan vektor batas bawah dan $\boldsymbol{b}$ yang merupakan vektor batas atas. Persamaan keseluruhan sistem proses dari model simulasi FCC acuan dapat dibagi ke dalam tujuh bagian proses seperti yang terlihat pada Tabel 1. Persamaan tersebut terdiri dari persamaan aljabar linear (PAL), persamaan aljabar nonlinear (PANL), persamaan diferensial ordiner (PDO), dan persamaan diferensial parsial (PDP).

Tabel 1. Persamaan yang digunakan pada model FCC

\begin{tabular}{cccccc}
\hline \multirow{2}{*}{ Bagian Proses } & \multicolumn{4}{c}{ Jenis Persamaan } & \multirow{2}{*}{ Jumlah } \\
\cline { 2 - 5 } & $\boldsymbol{P A L}$ & $\boldsymbol{P A N L}$ & $\boldsymbol{P D O}$ & $\boldsymbol{P D P}$ & \\
\hline Sistem Umpan & 4 & 0 & 0 & 0 & 4 \\
Sistem pemanas awal & 3 & 1 & 2 & 0 & 6 \\
Reaktor & 17 & 2 & 4 & 0 & 23 \\
Kompresor & 3 & 4 & 1 & 0 & 8 \\
Regenerator & 25 & 12 & 8 & 5 & 50 \\
Blower Udara & 7 & 11 & 3 & 0 & 21 \\
Sirkulasi Katalisator & 8 & 0 & 2 & 0 & 10 \\
\hline Jumlah & $\mathbf{6 7}$ & $\mathbf{3 0}$ & $\mathbf{2 0}$ & $\mathbf{5}$ & $\mathbf{1 2 2}$ \\
\hline
\end{tabular}

Namun demikian, model matematik FCC acuan [1] belum menyediakan model produk FCC. Model dari produk yang dihasilkan FCC harus tersedia pada simulator karena merupakan tujuan akhir FCC. Model matematik produk FCC dapat dimodelkan berdasarkan jumlah komponen yang digambarkannya. Parameter reaksi perengkahan pada FCC diestimasikan dalam 6 komponen [4]. Keenam komponen tersebut yaitu gas oil (a), diesel oil (b), gasoline (c), liquid petroleum gas (LPG) (d), light gas (e), dan coke (f) seperti terlihat pada Gambar 3. Pemodelan FCC pada emam komponen sebagai kategori produk industri kilang minyak. 


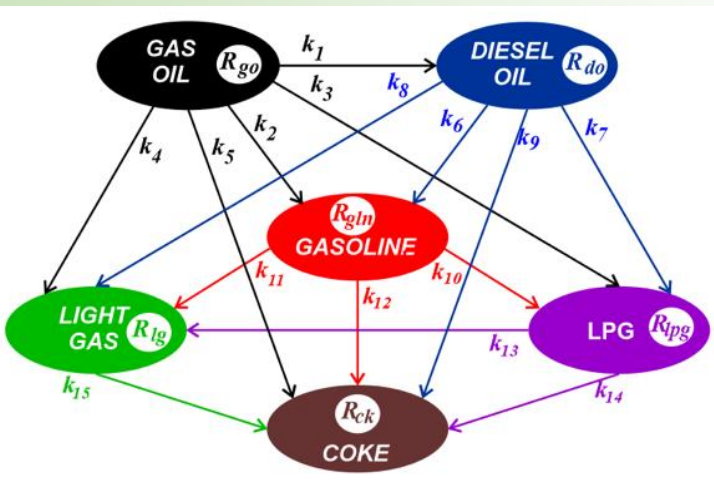

Gambar 3. Model produk FCC 6 komponen [4]

Masukan utama FCC adalah gas oil, sedangkan diesel oil dapat ditambahkan sebagai umpan. Produk utama FCC adalah gasoline, LPG, dan light gas. Coke adalah residu hasil perengkahan yang dapat menurunkan kereaktifan katalis. Gas oil sebagai masukan utama FCC dapat direngkahkan menjadi 5 (lima) komponen lainnya yaitu diesel oil, gasoline, LPG, light gas, dan coke. Diesel oil sebagai salah satu hasil perengkahan gas oil, kemudian dapat terengkahkan menjadi gasoline, light gas, LPG, dan coke. Gasoline sebagai produk utama FCC hasil perengkahan gas oil dan diesel, juga kemudian dapat terengkahkan menjadi light gas, LPG, dan coke. Coke merupakan residu hasil perengkahan yang dapat terbentuk dari setiap perengkahan 5 komponen lainnya.

Pemodelan produk FCC didefinisikan menggunakan persamaan dan parameter reaksi [2]. Parameter reaksi berupa frekuensi reaksi dan energi aktivasi untuk setiap skema reaksi perengkahan terlihat pada Tabel 2 .

Tabel 2. Parameter reaksi perengkahan [2].

\begin{tabular}{ccccc}
\hline No. & Masukan & Produk & $\begin{array}{c}\text { Frekuensi } \\
\text { Reaksi } \\
\left(\mathbf{s}^{\mathbf{- 1}}\right)\end{array}$ & $\begin{array}{c}\text { Energi } \\
\text { Aktivasi } \\
(\mathbf{k J} / \mathbf{k m o l})\end{array}$ \\
\cline { 2 - 4 } 1 & & Diesel oil & 7957,29 & 53927,7 \\
2 & Gasoline & 14433,40 & 57186,6 \\
3 & Gas oil & LPG & 2337,10 & 51308,6 \\
4 & & Light gases & 449,92 & 48620,4 \\
5 & & Coke & 40,25 & 32433,6 \\
\hline 6 & & Gasoline & 197,93 & 48114,5 \\
7 & \multirow{4}{*}{ Diesel oil } & LPG & 3,51 & 67792,9 \\
8 & & Light gases & 3,40 & 64266,6 \\
9 & & Coke & 75,28 & 61159,4 \\
\hline 10 & \multirow{4}{*}{ Gasoline } & LPG & 2,19 & 56194,4 \\
11 & & Light gases & 1,66 & 63319,1 \\
12 & \multirow{4}{*}{ LPG } & Coke & 2,03 & 61785,1 \\
\hline 13 & & Light gases & 3,41 & 55513,0 \\
14 & Light gases & Coke & 0,60 & 52548,2 \\
\hline 15 & & Coke & 2,20 & 53046,0 \\
\hline
\end{tabular}

\subsection{Pengembangan Antarmuka Simulator}

Antarmuka simulator FCC model IV berupa human machine interface (HMI) yang dikembangkan menggunakan perangkat lunak Node-RED [5]. Node-RED menggunakan struktur pemrograman yang berdasarkan aliran (flow) pesan (payloads) pada setiap blok fungsi (nodes). Kode program antarmuka simulator FCC diterapkan di dalam nodes "template" yang tersedia pada palette "dashboard".

Flow Node-RED dimulai dengan menerima payloads berupa variabel proses yang akan ditampilkan pada HMI seperti yang terlihat pada Gambar 4. Payloads akan diolah sebelum memasuki nodes "template" yang merupakan inti dari HMI. Pengolahan payloads berupa pengaturan nilai desimal (banyaknya angka di belakang koma yang akan ditampilkan pada HMI), penyaringan, dan penggabungan pesan. Pesan yang telah diolah kemudian memasuki blok fungsi 
template untuk ditampilkan pada HMI. Pengubahan variabel proses memungkinkan HMI mengirimkan pesan yang sebelumnya telah diolah.

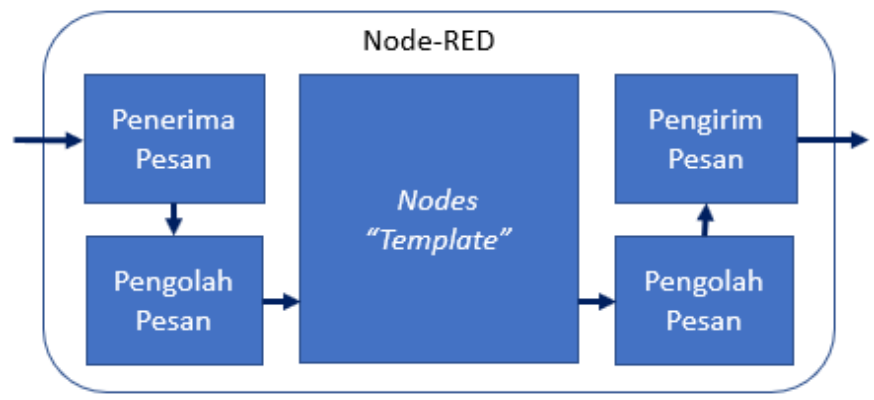

Gambar 4. Flow HMI simulator FCC pada Node-RED

Tampilan HMI dapat diatur sesuai kode program di dalam nodes template. Nodes template dapat ditulis menggunakan bahasa pemrograman untuk membuat sebuah tampilan web. Bahasa pemrograman yang dapat digunakan dengan menggunakan format HTML (Hypertext Markup Language), XML (eXtensible Markup Language), dan CSS (Cascading Style Sheet). Tampilan dasar HMI simulator FCC yang dikembangkan menggunakan vektor SVG (Scalable Vector Graphic) yang memungkinkan penggunaan data menjadi lebih efisien.

\subsection{Implementasi Protokol Komunikasi}

Simulator FCC menggunakan protokol komunikasi Message Queuing Telemetry Transport (MQTT) seperti yang terlihat pada Gambar 5. MQTT adalah protokol komunikasi berbasis publish dan subscribe pada broker. Broker merupakan penyedia data pada protokol komunikasi MQTT. Client dapat mengirimkan data menuju broker menggunakan publish, sedangkan meminta data menggunakan subscribe. Setiap pesan yang dikirim/diterima pada protokol komunikasi MQTT selalu memiliki topik. Topik inilah yang dapat menjadi identitas pesan sehingga dapat dibedakan antara pesan yang satu dengan yang lainnya. Simulator FCC yang dikembangkan menggunakan broker MQTT Mosquitto [6]. Perubahan variabel masukan pada HMI akan diterima oleh FCC Model yang menggunakan basis runtime environment FORTE [7]. Data variabel proses dari FCC model dikirimkan melalui protokol komunikasi MQTT kepada broker MQTT Mosquitto. HMI pada Node-RED meminta data variabel proses tersebut dari broker untuk ditampilkan.

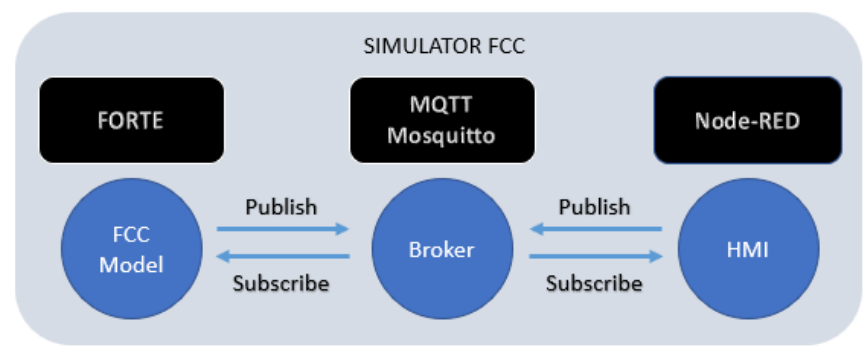

Gambar 5. Komunikasi data simulator FCC.

\subsection{Implementasi Standar IEC 61499}

Kebanyakan simulator FCC yang telah dikembangkan tidak dapat digunakan untuk melatih keterampilan operator. Hal ini karena simulasi acuan yang dibuat pada Matlab-Simulink tidak memungkinkan pengubahan variabel masukan ketika simulator tersebut dijalankan $[8,9,10,11]$. Standar IEC 61499 [12] diterapkan pada pengembangan simulator FCC pada penelitian ini agar memungkinkan pengubahan variabel masukan serta dapat mendistribusikannya pada perangkat keras yang berbeda.

Implementasi standar IEC 61499 dibagi menjadi tujuh bagian proses seperti yang terlihat pada Gambar 6. Setiap bagian proses menggambarkan setiap bagian pada sistem FCC. Setiap bagian FCC dimodelkan pada sebuah blok fungsi. 


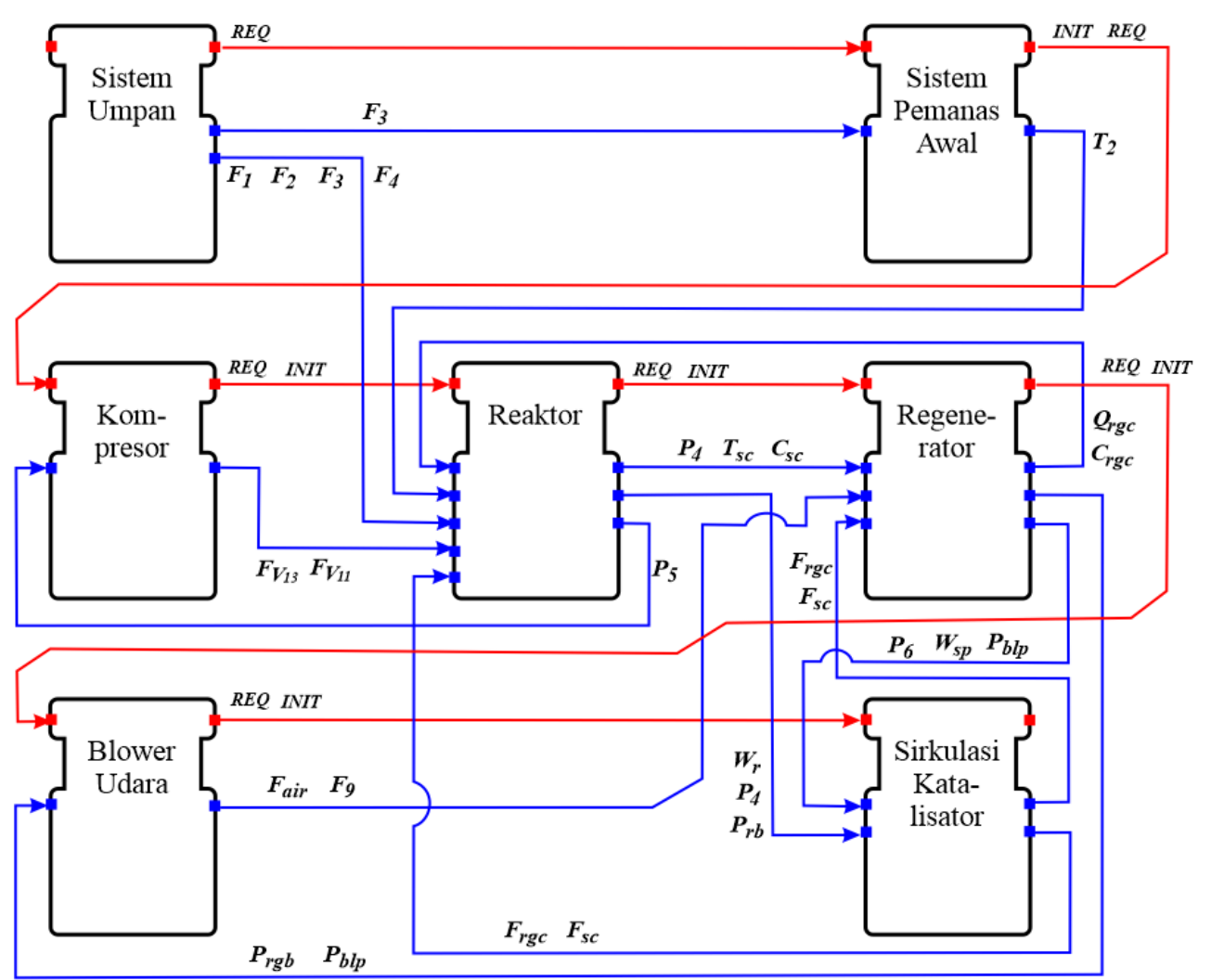

Gambar 6. Distribusi bagian proses pada IEC 61499

Tabel 3. Blok fungsi setiap bagian FCC

\begin{tabular}{cccccc}
\hline & \multirow{3}{*}{ Bagian Proses } & \multirow{2}{*}{ Tipe } & \multicolumn{4}{c}{ Masukan } & \multicolumn{2}{c}{ Keluaran } \\
\cline { 3 - 6 } & & Event & Data & Event & Data \\
\cline { 3 - 6 } & basic & 1 & 4 & 1 & 4 \\
Sistem Umpan & basic & 2 & 4 & 2 & 2 \\
Pemanas Awal & basic & 2 & 15 & 2 & 9 \\
Reaktor & basic & 2 & 4 & 2 & 4 \\
Kompresor & composite & 2 & 11 & 2 & 13 \\
Regenerator & basic & 2 & 10 & 2 & 7 \\
Blower Udara & basic & 2 & 6 & 2 & 2 \\
Sirkulasi Katalisator & & & &
\end{tabular}

Implementasi model matematik FCC menggunakan blok-blok fungsi jenis basic dan composite. Blok fungsi basic menggunakan pemrograman berbasis execution control chart (ECC) yang mengatur aliran algoritma program di dalam blok fungsi. Algoritma program ditulis dalam bahasa pemrograman structured text (ST) [12] yang mirip dengan bahasa C. Tipe blok fungsi basic merupakan tipe blok fungsi yang banyak digunakan pada pemodelan karena kemudahan pembuatan dan peninjauan ulang program. Blok fungsi regenerator menggunakan tipe composite. Tipe ini adalah tipe yang memungkinkan beberapa blok fungsi dibuat menjadi sebuah blok fungsi didalamnya. Tipe ini memudahkan pengorganisasian beberapa blok fungsi di dalam sebuah blok fungsi.

Setiap blok fungsi bagian proses memiliki masukan event dan data seperti terlihat pada Tabel 3. Hal ini karena pemodelan menggunakan standar IEC 61499 dimana eksekusi blok fungsi diatur melalui aliran event memasuki blok fungsi. Aliran eksekusi blok fungsi yang berbeda dengan aliran data merupakan salah satu keunggulan standar IEC 61499 dibanding standar IEC 61311 [13]. Setiap blok fungsi IEC 61499 harus memiliki minimal satu buah masukan event untuk menjalankannya. Jumlah event masukan dan keluaran selalu sama pada setiap blok fungsi bagian proses, namun hal ini tidak menjadi syarat standar IEC 61499. Jumlah aliran data masuk dan keluaran dapat berbedabeda sesuai dengan kebutuhan pemodelan. 
Blok fungsi setiap unit proses yang telah dibuat saling berhubungan sehingga menjadi model FCC. Aliran event dan data saling berhubungan antar blok fungsi seperti yang terlihat pada Gambar 7. Aliran event antar blok fungsi berupa event masukan INIT dan REQ, serta event keluaran INITO dan CNF. Masukan event INIT sebagai inisiasi blok fungsi pada awal simulasi berlangsung. Inisiasi diperlukan pada semua blok fungsi kecuali pada sistem umpan. Hal tersebut karena pada blok fungsi sistem umpan tidak terdapat nilai konstanta/parameter proses yang perlu diinisiasi. Simulator FCC dijalankan dengan terlebih dahulu terjadi event inisialisasi (INIT) pada pemanas awal, kemudian menuju kompresor, reaktor, regenerator, blower udara, dan sirkulasi katalisator. Inisiasi hanya terjadi satu kali di awal simulasi.

Penyelesaian persamaan proses di dalam blok fungsi diselesaikan dengan iterasi berulang sesuai dengan terjadinya event masukan REQ dan keluaran CNF pada masing-masing blok fungsi. Event REQ dimasukan pertama kali pada blok fungsi sistem umpan untuk mengeksekusi algoritma program didalamnya dan menyebabkan terjadinya event keluaran CNF. Event keluaran CNF tersebut dihubungkan dengan event masukan REQ pada blok fungsi sistem umpan dan juga mengeksekusi algoritma program untuk menyelesaikan persamaan proses didalamnya. Hubungan aliran event CNF dan REQ selanjutnya dilanjutkan pada blok fungsi kompresor, reaktor, regenerator, blower udara, dan sirkulasi katalisator. Urutan ekesekusi blok fungsi tersebut dibuat berdasarkan kebutuhan aliran data pada blok fungsi dan juga aliran proses yang terjadi pada FCC.

Aliran event untuk mengeksekusi blok fungsi dapat dihasilkan dari blok fungsi E_CYCLE yang terdapat di dalam pustaka 4DIAC-IDE. Aliran event yang dihasilkan dari blok fungsi ini terjadi secara berulang dengan periode sebesar DT (dalam ms). Adanya DT membuat eksekusi blok fungsi terjadi jeda waktu. Jeda waktu dapat diatur melalui aliran data DT pada antarmuka blok fungsi. Penulisan T\#20ms pada aliran data DT memiliki arti bahwa nilai jeda waktu sebesar 20 ms. Nilai DT perlu diatur agar mendapatkan hasil simulasi FCC yang bersifat memusat pada hasil yang konvergen. Nilai DT yang terlalu besar dapat menyebabkan hasil iterasi variabel FCC divergen sehingga nilainya terlalu besar dan melebihi kemampuan komputasi (nan).

Tabel 4. Blok fungsi setiap bagian FCC

\begin{tabular}{ccc}
\hline $\begin{array}{c}\text { Nilai DT } \\
(\mathbf{m s})\end{array}$ & $\begin{array}{c}\text { Rata-rata } \\
\text { Persentase } \\
\text { Kesalahan }\end{array}$ & $\begin{array}{c}\text { Persentase } \\
\text { Kesalahan } \\
\text { Terbesar }\end{array}$ \\
\hline 500 & \multicolumn{2}{c}{ divergen (nan) } \\
450 & \multicolumn{2}{|c}{} \\
400 & $1,82 \%$ & $9,54 \%$ \\
\hline 300 & $1,82 \%$ & $9,54 \%$ \\
250 & $1,81 \%$ & $9,30 \%$ \\
200 & $1,83 \%$ & $9,83 \%$ \\
150 & $1,89 \%$ & $10,88 \%$ \\
100 & $1,85 \%$ & $10,27 \%$ \\
50 & $1,83 \%$ & $9,93 \%$ \\
40 & $1,73 \%$ & $8,29 \%$ \\
30 & $1,63 \%$ & $6,55 \%$ \\
20 & $1,52 \%$ & $6,56 \%$ \\
10 & $1,35 \%$ & $6,57 \%$ \\
5 & $1,35 \%$ & $6,57 \%$ \\
2 & &
\end{tabular}

Nilai DT $400 \mathrm{~ms}, 450 \mathrm{~ms}$, dan $500 \mathrm{~ms}$ membuat hasil simulasi FCC bersifat bersifat divergen seperti terlihat pada Tabel 4. Hal ini ditunjukkan dengan nilai variabel proses berupa nan. Nilai DT lebih dari $400 \mathrm{~ms}$ tidak dapat digunakan pada simulator yang telah dibuat. Nilai DT $300 \mathrm{~ms}$ sudah cukup kecil untuk menghasilkan hasil iterasi yang bersifat konvergen. Hasil simulasi dengan rentang $2 \mathrm{~ms} \leq \mathrm{DT} \leq 300 \mathrm{~ms}$ memiliki rata-rata persentase kesalahan dari 1,35\% hingga 1,89\%. Rata-rata persentase kesalahan merupakan rata-rata persen perbedaan hasil simulasi yang telah dibuat terhadap hasil simulasi acuan pada 20 variabel proses yang ditinjau. Nilai rata-rata persentase kesalahan dan persentase kesalahan terbesar menunjukan kecenderungan yang semakin kecil ketika menggunakan nilai DT yang lebih kecil pula. 
HMI simulator FCC menampilkan setiap peralatan proses pada FCC sepeti terlihat pada Gambar 7. Nilai variabel proses dapat dipantau sebagai hasil simulasi. Variabel masukan pada simulator dapat diubah mengubah posisi katup. Perubahan ini dapat dilakukan meskipun simulasi FCC sedang berjalan. Hal inilah yang membuat simulator FCC yang dikembangkan dapat digunakan sebagai media pembelajaran bagi para operator untuk mempelajari dinamika proses yang terjadi. Simulasi FCC dapat dijalankan/dihentikan dengan menekan tombol start/stop. Simulasi FCC dapat dikembalikan ke keadaan semula dengan menekan tombol restart.

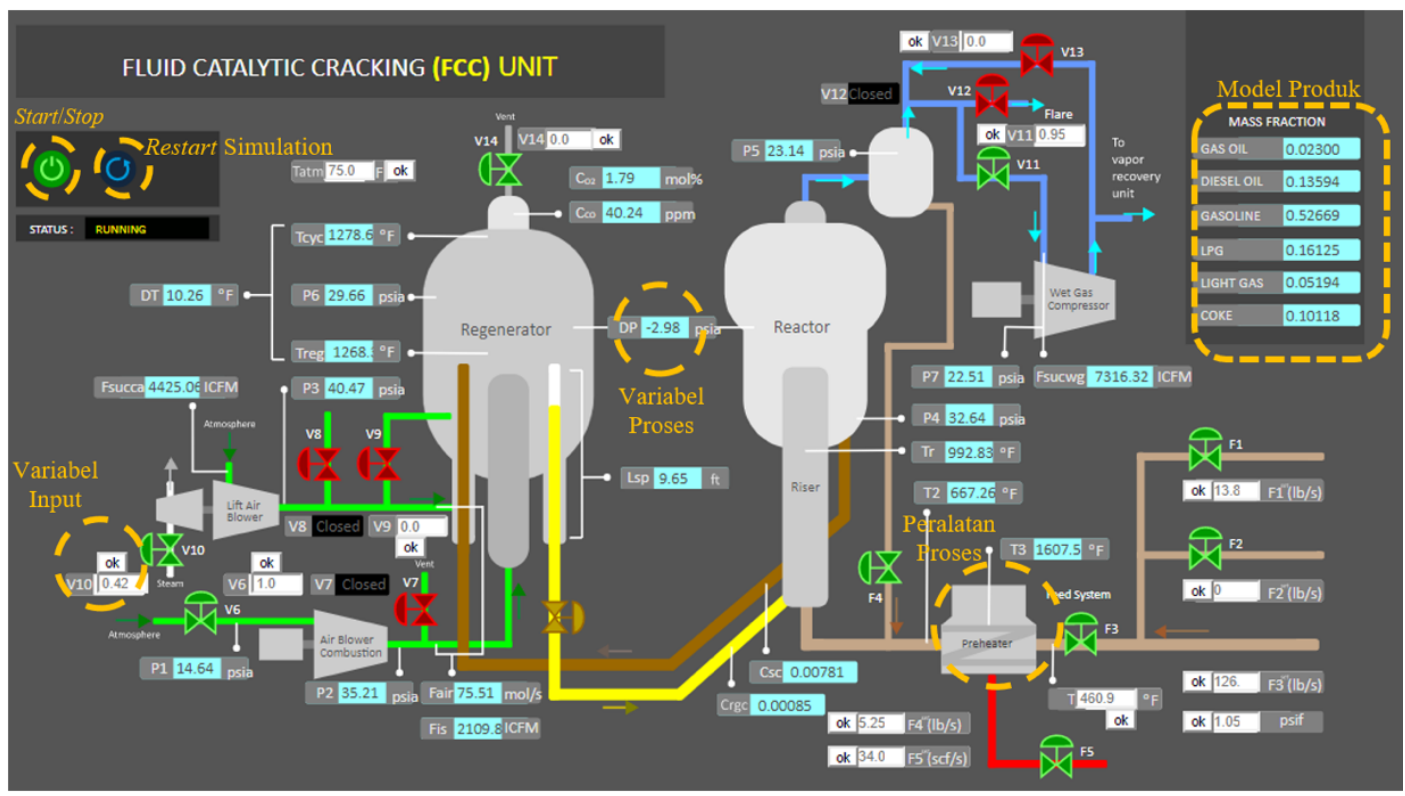

Gambar 7. Human machine interface (HMI) simulator FCC.

\section{Hasil dan Pembahasan}

Validasi perlu dilakukan untuk memastikan bahwa implementasi standar IEC 61499 pada pemodelan FCC memberikan hasil simulasi yang telah sesuai dengan model acuannya [1]. Validasi dilakukan pada empat variasi kondisi berdasarkan variabel pengganggu yang tersedia pada model simulasi. Keempat kondisi operasi yaitu kondisi operasi normal, perubahan coking factor, suhu atmosfer, dan suhu umpan seperti yang terlihat pada Tabel 5.

Tidak ada perubahan variabel pengganggu pada kondisi operasi normal. Kondisi operasi perubahan coking factor pada simulasi menggambarkan terjadinya perubahan karakteristik umpan masuk. Nilai coking factor berubah dari 1,00 menjadi 1,05. Kondisi operasi ketiga terjadi perubahan suhu atmosfer. Suhu atmosfer pada keadaan normal $75,0^{\circ} \mathrm{F}$ mengalami kenaikan menjadi $105,0^{\circ} \mathrm{F}$. Kondisi operasi keempat terjadi perubahan suhu umpan. Suhu umpan mengalami kenaikan dari kondisi normal $460,9^{\circ} \mathrm{F}$ menjadi $500,0^{\circ} \mathrm{F}$.

Nilai 20 variabel proses yang ditinjau pada simulasi FCC acuan dalam kondisi operasi normal bernilai tunak dari awal dijalankannya simulasi. Hasil simulasi FCC yang telah dibuat berdasar standar IEC 61499 membutuhkan waktu sekitar 4 menit untuk mencapai keadaan tunak. Simulasi FCC standar IEC 61499 juga menggunakan nilai kondisi awal variabel proses berdasarkan simulasi FCC acuan. Hasil simulasi FCC standar IEC 61499 membutuhkan waktu untuk mencapai nilai tunak. Hal tersebut karena penyelesaian simulasi FCC biasanya menggunakan logic solver, sedangkan pada simulasi FCC yang berbasis standar IEC 61499 menggunakan iterasi siklus secara berulang.

Simulasi FCC yang telah dibuat memiliki rerata persentase kesalahan dari 20 variabel proses sebesar 1,63\% seperti yang terlihat pada Tabel 6. Kesalahan ini bernilai sangat kecil, sehingga model simulasi FCC standar IEC 61499 yang telah dibuat dapat diterima. Nilai kesalahan variabel proses yang besar (melebihi 5\%) terjadi pada variabel proses selisih tekanan reaktor-regenerator $\left(\Delta P_{R R}\right)$, ketinggian katalis didalam stand pipe $\left(L_{s p}\right)$, perbedaan suhu regenerator bed dengan cyclone 
$(\Delta T)$, konsentrasi karbon monoksida pada gas buang $\left(C_{c o, s g}\right)$, dan aliran hisap blower udara pendorong $\left(F_{\text {sucn,lift }}\right)$. Nilai kesalahan terbesar pada $F_{\text {sucn,lijt }}$ yaitu $6,55 \%$. Hasil simulasi FCC pada kondisi operasi normal sudah dapat diterima.

Tabel 5. Variasi kondisi operasi proses.

\begin{tabular}{cccc}
\hline Kondisi Operasi & Coking Factor & Suhu Atmosfer $\left({ }^{\mathbf{0}} \mathbf{F}\right)$ & Suhu Umpan $\left({ }^{\mathbf{}} \mathbf{F}\right)$ \\
\hline Operasi normal & 1,00 & 75 & 460,9 \\
Perubahan coking factor & $1,00-1,05$ & 75 & 460,9 \\
Perubahan suhu atmosfer & 1,00 & $75-105$ & $460,9-500,0$ \\
Perubahan suhu umpan & 1,00 & 75 & 460,9 \\
\hline
\end{tabular}

Tabel 6. Perbandingan variabel proses hasil simulasi standar IEC 61499 dengan acuan [1] pada kondisi operasi normal.

\begin{tabular}{|c|c|c|c|c|}
\hline \multirow[b]{2}{*}{ Variabel Proses } & \multirow[b]{2}{*}{ Satuan } & \multicolumn{3}{|c|}{ Nilai Tunak Simulator } \\
\hline & & Acuan & IEC 61499 & $\begin{array}{l}\text { Persentase } \\
\text { kesalahan }\end{array}$ \\
\hline Tekanan reaktor $\left(P_{4}\right)$ & psia & 32,82 & 32,64 & $0,57 \%$ \\
\hline $\begin{array}{l}\text { Perbedaan tekanan antara } \\
\text { regenerator terhadap reaktor } \\
\qquad\left(\Delta P_{R R}\right)\end{array}$ & psia & $-3,15$ & $-2,97$ & $5,71 \%$ \\
\hline $\begin{array}{l}\text { Laju alir udara masuk } \\
\text { regenerator }\left(F_{T}\right)\end{array}$ & $\mathrm{mol} / \mathrm{s}$ & 75,54 & 75,52 & $0,02 \%$ \\
\hline Tekanan regenerator $\left(P_{6}\right)$ & psia & 29,67 & 29,66 & $0,03 \%$ \\
\hline $\begin{array}{l}\text { Suhu furnace pada sistem } \\
\text { pemanas awal }\left(T_{3}\right)\end{array}$ & ${ }^{\circ} \mathrm{F}$ & 1607,55 & 1607,55 & $0,00 \%$ \\
\hline $\begin{array}{l}\text { Suhu umpan keluar sistem } \\
\text { pemanas awal }\left(T_{2}\right)\end{array}$ & ${ }^{\circ} \mathrm{F}$ & 667,26 & 667,26 & $0,00 \%$ \\
\hline Suhu reaktor $\left(T_{r}\right)$ & ${ }^{\circ} \mathrm{F}$ & 992,66 & 992,81 & $0,02 \%$ \\
\hline Suhu regenerator $\left(T_{\text {reg }}\right)$ & ${ }^{\circ} \mathrm{F}$ & 1268,36 & 1268,36 & $0,00 \%$ \\
\hline $\begin{array}{l}\text { Ketinggian katalisator pada } \\
\text { stand pipe }\left(L_{s p}\right)\end{array}$ & $\mathrm{ft}$ & 10,16 & 9,63 & $5,24 \%$ \\
\hline $\begin{array}{l}\text { Suhu gas buang pada cyclone } \\
\left(T_{c y c}\right)\end{array}$ & ${ }^{\circ} \mathrm{F}$ & 1279,18 & 1278,61 & $0,04 \%$ \\
\hline $\begin{array}{c}\text { Perbedaan suhu regenerator-bed } \\
\text { dengan cyclone }(\Delta T)\end{array}$ & ${ }^{\circ} \mathrm{F}$ & 10,83 & 10,25 & $5,33 \%$ \\
\hline $\begin{array}{c}\text { Konsentrasi karbon monoksida } \\
\text { pada gas buang }\left(C_{c o, s g}\right)\end{array}$ & ppm & 37,02 & 39,43 & $6,50 \%$ \\
\hline $\begin{array}{c}\text { Konsentrasi oksigen pada gas } \\
\text { buang }\left(C_{o 2, s g}\right)\end{array}$ & $\% \mathrm{~mol}$ & 1,82 & 1,80 & $1,15 \%$ \\
\hline $\begin{array}{c}\text { Fraksi massa coke pada spent } \\
\text { catalyst }\left(C_{s c}\right)\end{array}$ & $\begin{array}{l}\text { lb cokel } \\
\text { lb katalis }\end{array}$ & 0,007812 & 0,007813 & $0,01 \%$ \\
\hline $\begin{array}{l}\text { Fraksi massa coke pada } \\
\text { regenerated catalyst }\left(C_{r g c}\right)\end{array}$ & $\begin{array}{l}\text { lb cokel } \\
\text { lb katalis }\end{array}$ & 0,000848 & 0,000851 & $0,38 \%$ \\
\hline $\begin{array}{l}\text { Laju alir masuk blower udara } \\
\text { pendorong }\left(F_{\text {sucn, lift }}\right)\end{array}$ & ICFM & 2003,04 & 2134,32 & $6,55 \%$ \\
\hline $\begin{array}{l}\text { Laju alir masuk kompresor } \\
\qquad\left(F_{\text {sucn,wg }}\right)\end{array}$ & ICFM & 7310,57 & 7315,90 & $0,07 \%$ \\
\hline $\begin{array}{l}\text { Laju alir masuk blower udara } \\
\text { pembakaran }\left(F_{\text {sucn,comb }}\right)\end{array}$ & ICFM & 4365,01 & 4404,36 & $0,90 \%$ \\
\hline $\begin{array}{c}\text { Tekanan hisap blower udara } \\
\text { pembakaran }\left(P_{l}\right)\end{array}$ & psia & 14,64 & 14,64 & $0,00 \%$ \\
\hline $\begin{array}{c}\text { Tekanan keluar blower udara } \\
\text { pembakaran }\left(P_{2}\right)\end{array}$ & psia & 35,22 & 35,21 & $0,01 \%$ \\
\hline
\end{tabular}

Perubahan kondisi operasi menyebabkan nilai variabel proses hasil simulasi menjadi berubah terhadap waktu hingga mencapai keadaan tunak-nya. Nilai variabel proses ditinjau setiap menit dan dibandingkan dengan nilai variabel FCC acuan. Persentase kesalahan antara hasil simulasi FCC standar IEC $61499\left(y_{\text {model, } i(t)}\right)$ dengan acuan $\left(y_{\text {model, } i(t)}\right)$ untuk setiap menit kemudian dihitung reratanya dengan Persamaan 5. Nilai ini disebut mean absolute percentage error (MAPE). Nilai MAPE dihitung untuk setiap 20 variabel proses yang ditinjau. Rata-rata nilai MAPE dari 20 variabel proses 
kemudian digunakan untuk memvalidasi model FCC standar IEC 61499 pada perubahan kondisi operasi.

$$
M A P E=\sum \frac{\left(\frac{\left(y_{\bmod e l, i(t)}-y_{\bmod e l, i(t)}\right)}{y_{\text {acuan }, i(t)}}\right)}{n} \times 100 \%
$$

Validasi simulator FCC juga dilakukan untuk mengetahui efek dari perubahan coking factor, suhu atmosfer, dan suhu umpan pada hasil simulator. Hal tersebut dijaga dalam waktu 3 jam untuk mencapai keadaaan tunak variabel FCC akibat perubahan-perubahan tersebut. Hasil validasi yang terlihat pada Tabel 7 menunjukkan bahwa nilai MAPE sebesar 4,40\% pada kondisi operasi perubahan coking factor merupakan nilai rata-rata dari 20 variabel proses. Nilai MAPE pada kondisi operasi perubahan suhu umpan sebesar $6,05 \%$ dan yang terbesar pada perubahan suhu atmosfer yaitu $7,26 \%$. Nilai tersebut menunjukan bahwa simulasi FCC standar IEC 61499 telah sesuai dengan simulasi FCC acuan.

Tabel 7. Nilai MAPE hasil simulasi variabel proses pada perubahan kondisi operasi

\begin{tabular}{ccc}
\hline Perubahan Kondisi Operasi & Simulasi & MAPE \\
\hline Perubahan coking factor & 3 Jam & $4,40 \%$ \\
Perubahan suhu atmosfer & 3 Jam & $7,26 \%$ \\
Perubahan suhu umpan & 3 Jam & $6,05 \%$ \\
\hline
\end{tabular}

Pada simulator terlihat seperti pada Gambar 8 bahwa fraksi massa coke pada spent catalyst $\left(C_{r g c}\right)$ meninggalkan reaktor memasuki regenerator sebesar $0,00781 \mathrm{lb}$ coke/lb katalis pada kondisi operasi normal. Perubahan kondisi operasi coking factor $\left(\psi_{f}\right)$, suhu umpan masuk $\left(T_{I}\right)$, dan suhu atmosfer $\left(T_{a t m}\right)$ menyebabkan perubahan nilai fraksi masa tersebut. Semakin besar nilai $\psi_{f}$, maka semakin banyak coke yang terbentuk dikarenakan $\psi_{f}$ merupakan karakteristik umpan pada pembentukan coke. Pada kondisi operasi normal, $\psi_{f}$ memiliki nilai 1 . Kenaikan nilai $\psi_{f}$ dari 1 menjadi 1,05 menyebabkan semakin banyak pembentukan coke pada reaktor. Hal ini menyebabkan fraksi massa coke pada spent catalyst meningkat menjadi $0,00860 \mathrm{lb}$ coke/lb katalis. Kenaikan fraksi massa coke pada perubahan kondisi operasi coking factor lebih besar dibandingkan kenaikan fraksi massa coke pada perubahan kondisi operasi $T_{l}$ maupun $T_{a t m}$.

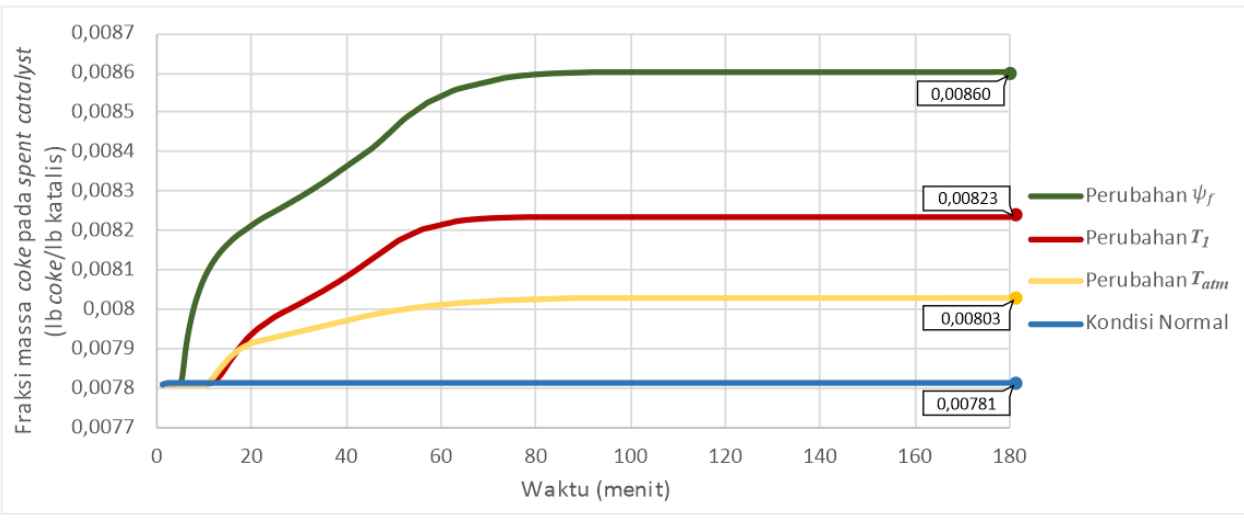

Gambar 8. Fraksi massa coke pada spent catalyst.

Fraksi massa coke pada spent catalyst $\left(C_{s c}\right)$ setelah proses regenerasi di dalam regenerator bernilai $0,00085 \mathrm{lb}$ coke/lb katalis pada kondisi operasi normal seperti telihat pada Gambar 9. Nilai fraksi massa coke mengalami perubahan saat proses regenerasi katalis, yakni bernilai $0,00781 \mathrm{lb}$ coke/lb katalis pada spent catalyst menjadi $0,00085 \mathrm{lb}$ coke/lb katalis pada regenerated catalyst. Hal tersebut memiliki arti bahwa pembakaran coke pada katalis di dalam regenerator sebesar $89,1 \%$ pada kondisi operasi normal seperti terlihat pada Gambar 10. Selama proses regenerasi berlangsung suhu atmosfer mengalami perubahan dari $75^{\circ} \mathrm{F}$ menjadi $105^{\circ} \mathrm{F}$. Perubahan suhu atmosfer menyebabkan kenaikan fraksi massa coke pada spent catalyst dari 0,00085 lb coke/lb katalis menjadi 0,00105 lb coke/lb katalis pada kondisi operasi normal. Kenaikan fraksi massa coke pada spent catalyst juga 
terjadi pada perubahan kondisi operasi lainnya, dengan kenaikan terbesar pada perubahan kondisi operasi coking factor.

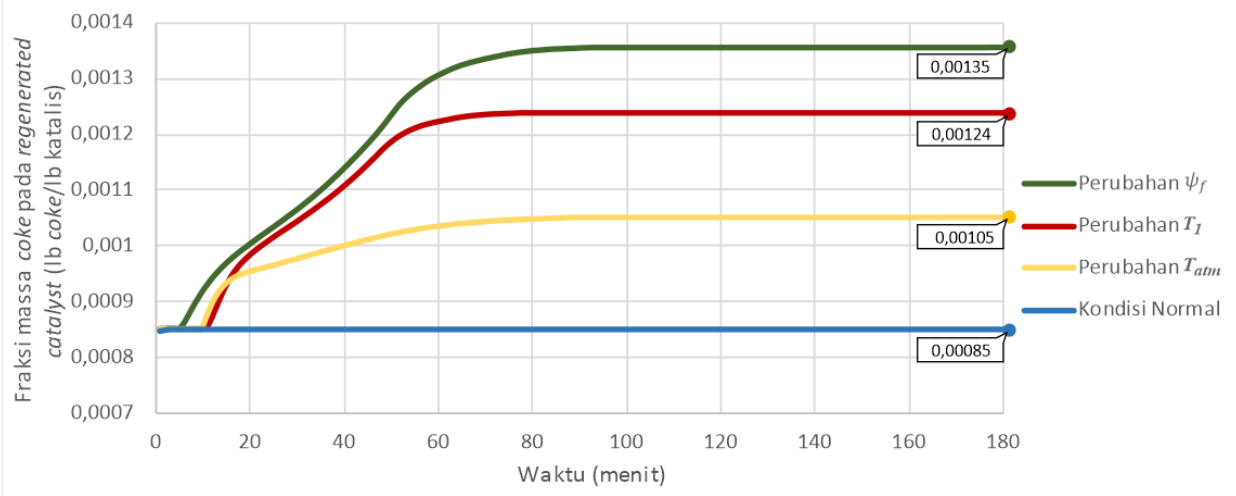

Gambar 9. Fraksi massa coke pada regenerated catalyst.

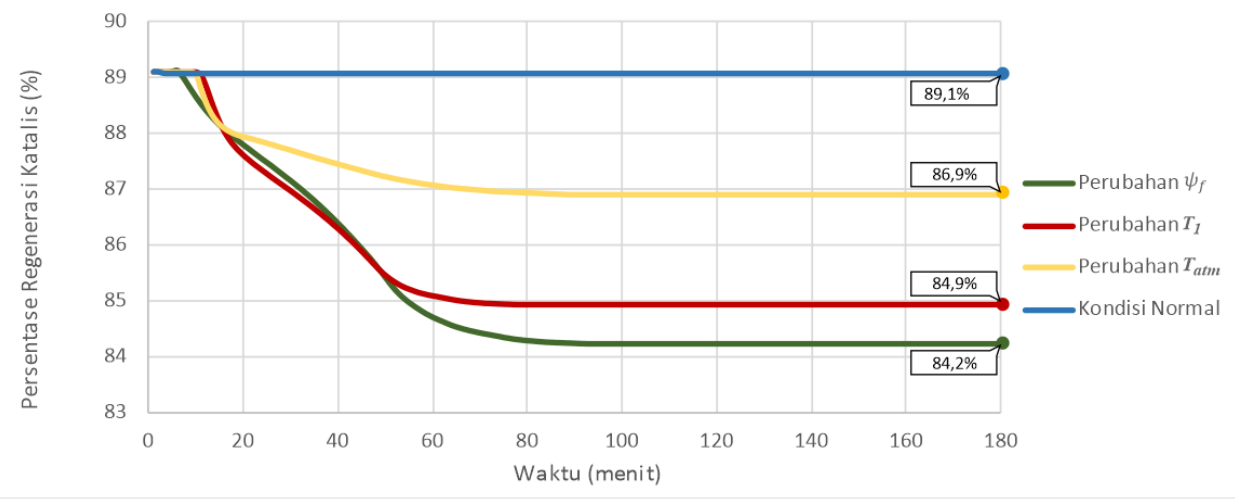

Gambar 10. Persentase regenerasi katalis pada berbagai kondisi operasi.

Validasi model produk juga dilakukan dengan cara membandingkan fraksi produk hasil simulasi dengan data pabrik [2] sesuai dengan Tabel 8. Hasil simulasi dibandingkan dengan cara memberi nilai masukan variabel proses yang sesuai dengan data pabrik. Variabel yang berpengaruh terhadap perengkahan pada FCC diantaranya rasio aliran massa katalis dengan umpan, suhu perengkahan, lamanya katalis didalam reaktor, dan fraksi coke pada katalis. Variabel masukan tersebut kemudian disamakan antara data pabrik dengan simulator.

Persen konversi adalah parameter penting pada perengkahan FCC. Fraksi massa gas oil keluar dari reaktor dapat digunakan untuk mencari nilai persen konversi proses [14]. Fraksi gas oil sebesar 0,0478 pada pabrik memiliki arti persen konversi sebesar 96,22\%. Persen konversi pada hasil simulasi sebesar $96,34 \%$, sehingga nilai kesalahan persen konversi hasil simulasi dibandingkan data pabrik sebesar $0,12 \%$.

Model produk kemudian digunakan pada empat buah kondisi operasi FCC. Kondisi operasi tersebut yaitu kondisi normal, perubahan coking factor, suhu atmosfer, dan suhu umpan. Jumlah fraksi massa pada berbagai kondisi operasi menunjukkan nilai yang sama yaitu 1,000 seperti ditampilkan pada Tabel 9. Nilai ini sudah sesuai karena walaupun fraksi massa setiap komponen berubah pada berbagai kondisi operasi, tetapi jumlah fraksi massanya harus sama dengan keadaan awal sebelum perengkahan.

Model simulasi terdistribusi adalah pendistribusian sumber daya komputasi (resources) ke dalam beberapa runtime environment FORTE. Pendistribusian resources menggunakan skema 1, 2, 4, dan 7 seperti terlihat pada Gambar 9. Simulasi FCC tersentralisasi pada 1 resources dibagi 2 buah resources. Masing-masing resources pada simulasi FCC terdistribusi 2 resources kemudian dibagi dua sehingga menjadi 4 resources. Kemudian setiap resources kembali dibagi dua (kecuali 
resources dengan sebuah blok fungsi regenerator), sehingga menghasilkan simulasi FCC terdistribusi pada 7 resources.

Tabel 8. Nilai MAPE hasil simulasi variabel proses pada perubahan variabel operasi.

\begin{tabular}{|c|c|c|c|}
\hline Variabel Proses & Satuan & $\begin{array}{c}\text { Data } \\
\text { Pabrik }\end{array}$ & Simulator \\
\hline \multicolumn{4}{|c|}{ MASUKAN } \\
\hline $\begin{array}{c}\text { Rasio aliran massa katalis dengan } \\
\text { umpan }\left(X_{\text {cat }, i}\right)\end{array}$ & lb katalis/ lb umpan & 6,405 & 6,405 \\
\hline Aliran massa katalis $\left(F_{c}\right)$ & $\mathrm{lb} / \mathrm{s}$ & 882,55 & 882,55 \\
\hline Aliran massa umpan $\left(F_{g}\right)$ & $\mathrm{lb} / \mathrm{s}$ & 137,79 & 137,79 \\
\hline Suhu umpan masuk reaktor $\left(T_{r, i}\right)$ & ${ }^{\circ} \mathrm{F}$ & 401,00 & 401,00 \\
\hline Suhu umpan keluar reaktor $\left(T_{r, o}\right)$ & ${ }^{\circ} \mathrm{F}$ & 932,09 & 932,09 \\
\hline $\begin{array}{l}\text { Waktu katalis dan umpan berada di } \\
\text { dalam reaktor }\left(\tau_{r}\right)\end{array}$ & $\mathrm{s}$ & N/A & 2,3875 \\
\hline $\begin{array}{c}\text { Fraksi coke pada katalis memasuki } \\
\text { reaktor }\left(C_{\text {cat,coke }}\right)\end{array}$ & $\mathrm{lb}$ coke/lb katalis & N/A & 0,00085 \\
\hline \multicolumn{4}{|c|}{ PRODUK } \\
\hline Fraksi massa gas oil $\left(R_{g o}\right)$ & lb gas oil/ lb umpan & 0,0478 & 0,0466 \\
\hline Fraksi massa diesel oil $\left(R_{d o}\right)$ & $\mathrm{lb}$ diesel oil/lb umpan & 0,1857 & 0,2034 \\
\hline Fraksi massa gasoline $\left(R_{\text {gln }}\right)$ & lb gasoline / lb umpan & 0,4731 & 0,3965 \\
\hline Fraksi massa LPG $\left(R_{l p g}\right)$ & lb LPG/lb umpan & 0,1518 & 0,1566 \\
\hline Fraksi massa light gases $\left(R_{l g}\right)$ & lb light gases / lb umpan & 0,0483 & 0,0527 \\
\hline Fraksi massa coke $\left(R_{\text {coke }}\right)$ & lb coke/lb umpan & 0,0891 & 0,1442 \\
\hline
\end{tabular}

Tabel 9. Fraksi massa pada berbagai kondisi operasi hasil simulasi FCC

\begin{tabular}{ccccc}
\hline \multirow{2}{*}{ Variabel Proses } & Normal & \multicolumn{3}{c}{ Kondisi Operasi } \\
\cline { 3 - 5 } & & Coking factor & Suhu Atmosfer & Suhu Umpan \\
\cline { 3 - 5 } & 0,0220 & 0,0197 & 0,0204 & 0,0172 \\
Fraksi massa gas oil $\left(R_{\text {go }}\right)$ & 0,1351 & 0,1210 & 0,1255 & 0,1043 \\
Fraksi massa diesel oil $\left(R_{\text {do }}\right)$ & 0,5269 & 0,5412 & 0,5366 & 0,5672 \\
Fraksi massa gasoline $\left(R_{\text {gln }}\right)$ & 0,1615 & 0,1620 & 0,1618 & 0,1619 \\
Fraksi massa LPG $\left(R_{\text {lpg }}\right)$ & 0,1612 & 0,0523 & 0,0519 \\
Fraksi massa light gases $\left(R_{l g}\right)$ & 0,0521 & 0,0524 & 0,1033 & 0,0974 \\
Fraksi massa coke $\left(R_{\text {coke }}\right)$ & 0,1024 & 0,1037 & 1,0000 & 1,0000 \\
\hline Jumlah & 1,0000 & 1,0000 & &
\end{tabular}

Analisis pengaruh jumlah resources dilakukan dengan membandingkan nilai rata-rata penggunaan memori berdasarkan jumlah resources yang digunakan. Variasi dilakukan pada model simulasi tersentralisasi 1 resources dan terdistribusi pada 2, 4, dan 7 resources. Masing-masing model simulasi dijalankan dan dipantau penggunaan memorinya menggunakan program yang telah dibuat pada Python. Setiap simulasi dijalankan selama 3 jam dengan pencuplikan penggunaan memori setiap menit. Penggunaan memori yang relatif tetap terhadap waktu dikarenakan jenis memori yang dipantau adalah private memory. Memori jenis ini merupakan memori yang spesifik digunakan oleh suatu proses tertentu selama proses tersebut dijalankan. Private memory dapat digunakan untuk mengetahui seberapa besar memori yang dibutuhkan untuk menjalankan proses tertentu. Simulasi FCC dengan 1 resource merupakan sistem tersentralisasi. Simulasi tersebut pada membutuhkan penggunaan memori sebesar 300,20 MB seperti terlihat pada Tabel 10. Kebutuhan memori ini merupakan kebutuhan memori terbesar. Hal ini dikarenakan seluruh perhitungan FCC dilakukan pada sebuah runtime environment FORTE. Persentase pengurangan memori merupakan persentase berkurangnya memori yang dibutuhkan simulasi terdistribusi terhadap simulasi tersentralisasi seperti terlihat pada Tabel 10. Penggunaan memori pada 1 resources menjadi acuan perhitungan ini karena merupakan pembanding simulasi tersentralisasi dengan terdistribusi pada 2 , 4, dan 7 resources. 


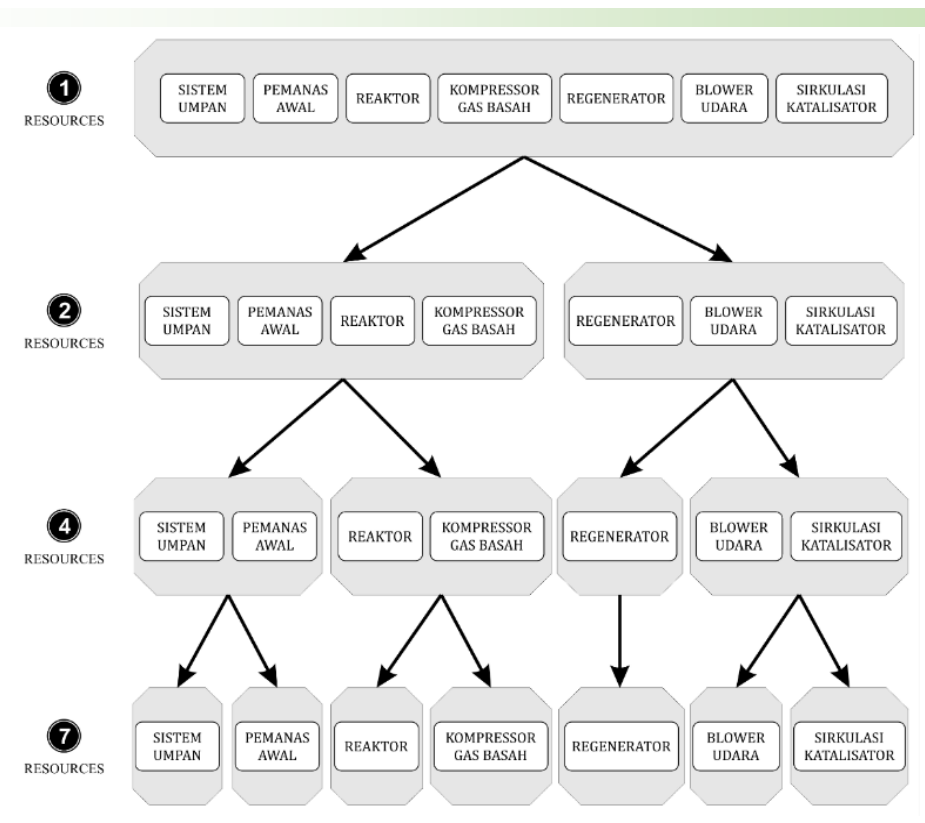

Gambar 11. Skema pendistribusian resources [15].

Tabel 10. Pengaruh jumlah resources terhadap rata-rata penggunaan memori (MB)

\begin{tabular}{cccc}
\hline Sistem & $\begin{array}{c}\text { Jumlah } \\
\text { Resources }\end{array}$ & $\begin{array}{c}\text { Rata-rata } \\
\text { Penggunaan } \\
\text { Memori (MB) }\end{array}$ & $\begin{array}{c}\text { Persentase } \\
\text { Pengurangan } \\
\text { Memori }\end{array}$ \\
\hline Tersentralisasi & 1 & 300,20 & - \\
\hline \multirow{2}{*}{ Terdistribusi } & 2 & 246,23 & $18.0 \%$ \\
& 4 & 192,24 & $36.0 \%$ \\
& 7 & 153,69 & $48.8 \%$ \\
\hline
\end{tabular}

Simulasi FCC dengan 2 resources membutuhkan penggunaan memori sebesar 246,23 MB. Kebutuhan ini 18,0\% lebih kecil dibandingkan penggunaan memori pada simulasi FCC 1 resources yang merupakan sistem tersentralisasi. Pengurangan memori tidak mencapai $50 \%$ pada pendistribusian dari 1 menjadi 2 resources. Hal ini karena pendistribusian simulasi menyebabkan kebutuhan komunikasi data (variabel proses) antar blok fungsi pada resources yang berbeda. Persentase pengurangan memori sebesar 36,0\% pada simulasi terdistribusi 4 resorces, hingga 48,8\% pada simulasi dengan 7 resources. Hal ini menunjukkan bahwa semakin banyak resources maka semakin kecil rata-rata penggunaan memori simulasi. Pendistribusian resources dapat mengurangi rata-rata kebutuhan penggunaan memori.

\section{Kesimpulan}

Simulator FCC model yang telah dikembangkan berbasis standar IEC 61499 dapat menjadi solusi kebutuhan media simulasi untuk melatih keterampilan operator. Simulator yang dibangun tersebut telah tervalidasi dibandingkan model FCC acuan [1] dengan rata-rata persentase kesalahan tunak sebesar 1,63\% pada kondisi operasi normal. Nilai MAPE simulator sebesar 4,40\% untuk perubahan coking factor, 7,26\% untuk perubahan suhu atmosfer, dan 6,05\%, untuk perubahan suhu umpan. Simulator yang dikembangkan mengakomodasi produk FCC yang terdiri dari 6 (enam) komponen yaitu gas oil, diesel oil, gasoline, LPG, light gas, dan coke. Perbandingan persen konversi gas oil antara hasil simulasi dengan data pabrik yang tersedia memiliki kesalahan sebesar $0,12 \%$. Model produk telah tervalidasi berdasar nilai total fraksi untuk empat kondisi operasi yang diuji. Pendistribusian model pada simulator FCC berbasis standar IEC 61499 dapat mengurangi penggunaan memori pada simulator sebesar 18,0\% untuk penggunaan dengan menggunakan 2 resources, 36,0\%, untuk penggunaan dengan menggunakan 4 resources dan $48,8 \%$ untuk penggunaan dengan menggunakan 7 resources. 


\section{Daftar Pustaka}

[1] R. C. McFarlane, R.C. Reinemann, J. F. Bartee, and C. Georgakis, "Dynamic simulator for a model IV fluid catalytic cracking unit," Computers Chemical Engineering, vol. 17, no. No. 3, pp. 275 - 300, 1993.

[2] R. Sadeghbeigi, Fluid catalytic cracking, an expert guide to the practical operation, design, and optimization of FCC units, 3rd ed., Elsevier, 2012.

[3] I.S. Han, C.-B. Chung, "Dynamic modeling and simulation of a fluidized catalytic cracking process," Chemical Engineering Science," vol. 1, no. 56, pp. 1951-1971, 2001.

[4] Y. M. John, M. A. Mustafa, R. Patel, and I. M. Mujtaba, "Parameter estimation of a six-lump kinetic model of an industrial fluid catalytic cracking unit," Fuel, vol. 235 , pp. 1436-1454, 2019.

[5] M. Blackstock, R. Lea,'Toward a distributed data flow platform for the web of things (distributed nodered)," in Proceedings of the 5th International Workshop on Web of Things, pp. 34-39, 2014.

[6] R. Light, "Mosquitto: server and client implementation of the MQTT protocol." Journal of Open Source Software vol. 2, no. 13, 2017.

[7] L. Prenzel., A. Zoitl and J. Provost. "IEC 61499 runtime environments: A state of the art comparison." in Proceedings of 17th International Conference on Computer Aided Systems Theory, 2019.

[8] D. F. Ahmed, and S. K. Ateya. "Modelling and simulation of sluid catalytic cracking unit," Journal of Chemical Engineering and Process Technology, vol. 7, 2016.

[9] A, Dhia. "A study of the dynamics and control of the model IV fluidized catalytic cracking process," Journal of Petroleum Research \& Studies., vol. 377, no.10, pp. 1-26. 2014.

[10] V. A.Akpan, R. Osakwe, and J. C. Onyekannankea, "Mathematical modeling and dynamic simulation of the FCCU-SHOF: Case Study of Warri Refinery (WRPC), Nigeria," Journal of Advanced Research in Instrumentation and Control Engineering, vol. 2, no.1, pp1-28, 2015.

[11] A. P. Jaimon, and P. S. H. Jose,'Temperature control of catalytic cracking process." in Proceedings of 2015 International Conference on Innovations in Information, Embedded and Communication Systems (ICIIECS). pp. 1-5. 2015.

[12] V. Vyatkin. "The IEC 61499 standard and its semantics," IEEE Industrial Electronics Magazine, vol. 3 no. 4, pp. 40-48, 2009.

[13]A. Zoitl, T. Strasser, C. Sunder, and T. Baier, "Is IEC 61499 in harmony with IEC 61131-3?. IEEE Industrial Electronics Magazine, vol.3, no.4, 2009.

[14]R. Sundaralingam, "Optimization of a model IV fluidized catalytic cracking unit," Canadian Jornal of Chemical Engineering, vol 76, no. 4, pp. 542-547, 2001.

[15]W. Fatkhurrohman, Penerapan standar IEC 61499 pada pemodelan sistem terdistribusi proses fluid catalytic cracking model IV, Skripsi, Yogyakarta: Universitas Gadjah Mada, 2019. 